\title{
Waterborne Electrospinning of Alpha-lactalbumin Generates Tunable and Biocompatible Nanofibers for Drug Delivery
}

Bay Stie, Mai; Corezzi, Michele; Juncos Bombin, Adrian D.; Ajalloueian, Fatemeh; Attrill, Erin; Pagliara, Stefano; Jacobsen, Jette; Chronakis, loannis S.; Mørck Nielsen, Hanne; Foderà, Vito

\section{Published in:}

ACS Applied Nano Materials

Link to article, DOI:

10.1021/acsanm.9b02557

Publication date:

2020

Document Version

Version created as part of publication process; publisher's layout; not normally made publicly available

Link back to DTU Orbit

Citation (APA):

Bay Stie, M., Corezzi, M., Juncos Bombin, A. D., Ajalloueian, F., Attrill, E., Pagliara, S., Jacobsen, J., Chronakis, I. S., Mørck Nielsen, H., \& Foderà, V. (2020). Waterborne Electrospinning of Alpha-lactalbumin Generates Tunable and Biocompatible Nanofibers for Drug Delivery. ACS Applied Nano Materials , 3(2), 1910-1921. https://doi.org/10.1021/acsanm.9b02557

\section{General rights}

Copyright and moral rights for the publications made accessible in the public portal are retained by the authors and/or other copyright owners and it is a condition of accessing publications that users recognise and abide by the legal requirements associated with these rights.

- Users may download and print one copy of any publication from the public portal for the purpose of private study or research.

- You may not further distribute the material or use it for any profit-making activity or commercial gain

- You may freely distribute the URL identifying the publication in the public portal 


\title{
Waterborne Electrospinning of $\alpha$-Lactalbumin Generates Tunable and Biocompatible Nanofibers for Drug Delivery
}

\author{
Mai Bay Stie, Michele Corezzi, Adrian D. Juncos Bombin, Fatemeh Ajalloueian, Erin Attrill, \\ Stefano Pagliara, Jette Jacobsen, Ioannis S. Chronakis, Hanne Mørck Nielsen, and Vito Foderà*
}

Cite This: https://dx.doi.org/10.1021/acsanm.9b02557

ABSTRACT: Protein-based drug carriers are an interesting alternative to traditional polymeric drug delivery systems due to their intrinsic biocompatibility and biodegradability. Electrospinning of neat proteins holds advantages over electrospinning of protein mixtures, e.g., whey isolates, such as better control of the physicochemical and biological function of the resulting nanofiber-based system. In this study, we explore electrospinning of the isolated milk protein $\alpha$-lactalbumin (ALA), which is a whey protein with important nutritional and pharmacological properties. Via waterborne electrospinning of ALA with a minimum amount of poly(ethylene oxide) (PEO) as a cospininng polymer, nanofibers of high protein content were successfully produced (up to $84 \%(\mathrm{w} / \mathrm{w})$ ). We demonstrate the ability to produce ALA-based nanofibers with a high degree of tunability in

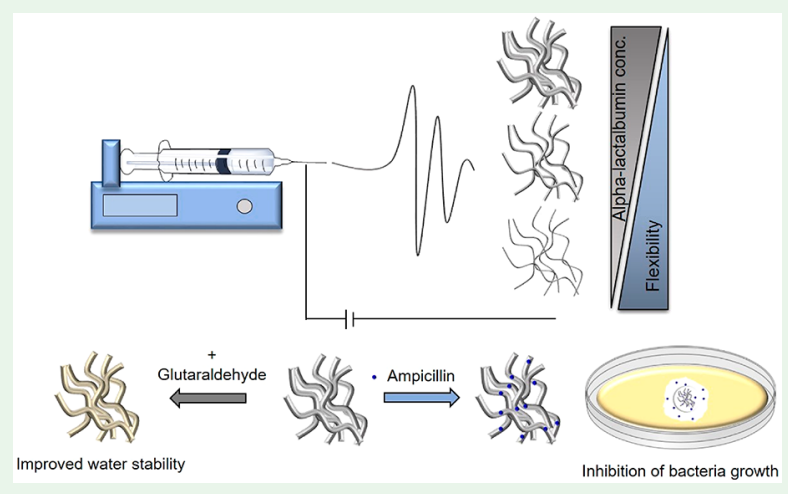
terms of size, stability in water, and mechanical properties. The nanofibers displayed excellent biocompatibility in vitro as the viability of cultured TR146 human buccal epithelium and NIH 3 T3 murine fibroblast cells was not influenced by exposure to ALA-based nanofibers. ALA-based nanofibers were loaded with up to $6 \%$ (w/w) ampicilin, and the nanofibers were capable of maintaining the activity of the antibiotic after electrospinning and cross-linking. Using such a property of the material, we demonstrate that ampicillin-loaded nanofibers successfully inhibit the growth of Gramnegative bacteria in vitro. Importantly, after treatment with ampicillin-loaded nanofibers, no bacterial regrowth was observed, which indicates that this treatment may clear eventual persisters to ampicillin. Finally, the structural properties of the native functional protein were maintained after release of ALA from the nanofibers. This promotes our platform, not only as a sustainable proteinbased drug delivery system, but also as an innovative solid form of ALA for food and pharmaceutical applications.

KEYWORDS: electrospinning, $\alpha$-lactalbumin, drug delivery, sustainable protein-based materials, Gram-negative bacteria, antibiotics, green chemistry

\section{INTRODUCTION}

Drug delivery systems (DDSs) based solely on synthetic polymers often have lower biocompatibility compared to DDS composed of polymers of natural origin, which may limit their applicability. ${ }^{1}$ Protein- or peptide-based nanocarriers are an interesting alternative to other polymeric drug delivery systems due to their intrinsic biocompatibility and biodegradability. ${ }^{2}$ Indeed, the large heterogeneity of proteins and peptides encoded in their primary amino acid sequence and the possibility of introducing chemical surface modifications hold great potential for a drug delivery platform with high tunability. Notwithstanding these extraordinary properties, high-performance protein-based DDSs are largely dependent on the morphology of the composite and, as a consequence, on a detailed control of the material development.

Electrospinning of polymer or protein solutions is a versatile method to form elongated fiber structures. In healthcare, electrospun fibers have found specific applications as DDSs, especially for topical administration, because of their high surface-to-volume ratio, porous structure, small size, and ability to delivery drugs in a controlled manner. ${ }^{3}$ However, strong acids and/or toxic solvents are often employed to dissolve the polymers for electrospinning. ${ }^{4}$ This has recently induced an increasing demand of more sustainable approaches, namely waterborne electrospinning, i.e., electrospinning from aqueous phases to ease clinical translation. This, of course, poses some limitations on the range of molecules that can be electrospun. ${ }^{4}$ With this idea in mind, considerable efforts have recently been devoted to electrospin proteins with the possibility to use water and avoid harmful or toxic solvents for the electro-

Received: December 23, 2019

Accepted: January 8, 2020

Published: January 8, 2020 
spinning. ${ }^{2}$ A wide variety of proteins such as gelatin, collagen, elastin, and silk have successfully been electrospun into nanofibers. ${ }^{3,5}$ The potential applications of protein-based nanofibers are diverse, and some have already been demonstrated, e.g., insoluble bovine serum albumin (BSA)/ PEO nanofibers as a two-dimensional biosensor or as scaffolds for cell growth ${ }^{6}$ or BSA/polycaprolactone (PCL) nanofibers as a DDS for sustained release of nerve growth factor (NGF) over 28 days. $^{7}$ Furthermore, successful attempts to electrospin whey protein isolates and other proteins such as $\beta$-globulin were reported. $^{8-10}$ However, electrospinning of whole protein mixtures may limit the bioactivity of a specific protein component of interest in the mixture as well as posing some constraints in the range of tunability of the final material.

Milk proteins represent ideal vectors for drug delivery due to their inherent role as vehicles that deliver small molecules in vivo. ${ }^{11}$ Moreover, they are cheap and readily available, which make them attractive for commercial use. ${ }^{11,12} \alpha$-Lactalbumin (ALA) is a $14.2 \mathrm{kDa}$ protein, a significant component of whey, which has several favorable properties, not only related to its nutritional function. Clinical studies showed that an ALAenriched diet was beneficial to patients vulnerable to stress by reducing cortisol levels and increasing cognitive and motor performances. ${ }^{13-15}$ In healthy subjects, administration of ALA increased sustained alertness and reduced sleepiness. ${ }^{16}$ ALA has been added to infant formula due to its intrinsic safety and for its ability to induce weight gain and prevent atopic dermatitis. $^{17-19}$ In its original, methylated, or chemically modified form, ALA showed inhibiting activity toward human immunodeficiency virus 1 (HIV-1), herpes simplex virus (HSV), and human cytomegalovirus. ${ }^{20}$ Furthermore, a partially unfolded form of ALA in combination with oleic acid, called HAMLET (human $\alpha$-lactalbumin made lethal to tumor cells), exerts in vitro a robust anticancer activity against a variety of tumor cell types. ${ }^{21,22}$ In vivo, HAMLET has been reported to show efficacy against papilloma, bladder cancer, glioblastoma, and colon cancer. ${ }^{23-26}$ In addition, the complex formed by bovine ALA and oleic acid, called BAMLET, has shown similar antitumor properties. ${ }^{27}$ For all the above cases, designing efficient formulations of ALA-based complexes in terms of both stability and capability of interacting with biological interfaces/barriers is fundamental.

Here, we successfully present a waterborne electrospinning protocol for the production of biocompatible electrospun ALA/PEO nanofibers. Besides the possibility to electrospin ALA without the use of any organic or toxic agents and with a minimum amount of copolymer, we also report a unique, easily scalable, tunability of our system. Size, mechanical properties, and wettability of the produced ALA nanofibers can indeed be rationally tuned by controlling the protein concentration and/ or via a nondestructive, simple, and sustainable postproduction treatment, which is a true novelty for materials composed by almost-net protein content. Most importantly, besides the above-mentioned versatility, ALA nanofibers are capable of encapsulating the antibiotic ampicillin, preserving the functionality of the antibiotic, and facilitating its delivery. We demonstrate this via monitoring the efficacy of ampicillinloaded nanofibers to inhibit the growth of relevant Gramnegative bacteria and eventually also clearing persisters bacteria to ampicillin. Last but not least, ALA in the form of nanofibers maintains its structural native features, which paves the way for conceptually novel solid formulations of biologics with enhanced stability and interesting interaction with biological interfaces.

\section{MATERIALS AND METHODS}

Materials. $\alpha$-Lactalbumin powder was kindly provided by Davisco Food International/Agropur Ingredients, Eden Prairie, MN (batch number: JE 010-5-410, 92.5\% purity). Poly(ethylene oxide) (PEO, $\left.M_{\mathrm{w}} 300 \mathrm{kDa}\right), 25 \%(\mathrm{w} / \mathrm{w})$ glutaraldehyde, Dulbecco's Modified Eagle's Medium-high glucose, L-glutamine, penicillin, streptomycin, Hank's Balanced Salt Solution (HBSS), and phenazine methosulfate (PMS) were purchased from Sigma-Aldrich (St. Louis, MO). NIH 3T3 cell line was from American Type Culture Collection (ATCC, Manassas, VA). TR146 cell line was kindly provided by the Imperial Cancer Research Technology (London, UK) with generous help from Prof. E. B. Lane (The University of Dundee, UK). Fetal bovine serum (FBS) was purchased from PAA Laboratories (Brøndby, Denmark). Newborn Calf Serum (NCS) was obtained from Life Technologies (Carlsbad, CA). N-2-Hydroxyethylpiperazine- $N^{\prime}$-2-ethanesulfonic acid (HEPES) was from PanReac AppliChem (Damstadt, Germany). 3-(4,5-Dimethylthiazol-2-yl)-5-(3-carboxymethoxyphenyl)-2-(4-sulfophenyl)-2H-tetrazolium) (MTS) was obtained from Promega (Madison, WI). Lysogeny broth (LB) medium ( $10 \mathrm{~g} / \mathrm{L}$ tryptone, 5 $\mathrm{g} / \mathrm{L}$ yeast extract, and $0.5 \mathrm{~g} / \mathrm{L} \mathrm{NaCl}$ ) and $\mathrm{LB}$ agar plates (LB with 15 $\mathrm{g} / \mathrm{L}$ agar) were used for planktonic growth and the growth inhibition study, respectively. Escherichia coli BW25113 was purchased from Dharmacon (GE Healthcare, Chicago, IL). Pseudomonas aeruginosa PA14, Burkholderia thailandensis E264, E. coli ATCC11303, and E. coli BW25113 carrying an ampicillin resistance cassette were kindly provided by Dr. E. Westra, Prof. R. Titball, and Dr. B. Temperton at University of Exeter and Dr. D. Summers at the University of Cambridge, respectively. Ultrapure water was obtained by purification on a PURELAB flex system (ELGA LabWater, High Wycombe, UK).

Preparation of Samples for Electrospinning. A list of samples is provided in Table 1. A 7.4\% $(\mathrm{w} / \mathrm{w})$ dispersion of PEO in ultrapure

Table 1. PEO and ALA Stock Solutions of the Listed Concentration Mixed in the Ratio 1:1 (w/w) and Electrospun $^{a}$

\begin{tabular}{cccccc} 
& \multicolumn{2}{c}{$\begin{array}{c}\text { concentration } \\
\text { (solution), } \%(\mathrm{w} / \mathrm{w})\end{array}$} & & \multicolumn{2}{c}{$\begin{array}{c}\text { content } \\
\%(\mathrm{w} / \mathrm{w})\end{array}$} \\
\cline { 2 - 3 } \cline { 5 - 6 } sample name & PEO & ALA & & PEO & ALA \\
ALA/PEO-0 & 7.4 & & & 100 & \\
ALA/PEO-39 & 7.4 & 4.8 & & 61 & 39 \\
ALA/PEO-55 & 7.4 & 9.1 & & 45 & 55 \\
ALA/PEO-69 & 7.4 & 16.7 & & 31 & 69 \\
ALA/PEO-76 & 7.4 & 23.1 & & 24 & 76 \\
ALA/PEO-79 & 7.4 & 28.6 & & 21 & 79 \\
ALA/PEO-84 & 7.4 & 37.5 & & 16 & 84 \\
ALA/PEO-100 & & 37.5 & & & 100
\end{tabular}

${ }^{a}$ The final PEO and ALA contents in the dry nanofibers are specified. Sample names are provided and will be used in the main text.

water was mixed in the ratio $1: 1(\mathrm{w} / \mathrm{w})$ with ALA solutions prepared in ultrapure water with ALA concentrations of 4.8, 9.1, 16.7, 23.1, 28.6, and $37.5 \%(\mathrm{w} / \mathrm{w})$ to obtain a final ALA content in the electrospun fibers of $39,55,69,76,79$, and $84 \%(w / w)$, respectively (Table 1).

For the production of ampicillin loaded fibers, ampicillin was dissolved in the ALA solution, which was mixed 1:1 (w/w) with a $7.4 \%(\mathrm{w} / \mathrm{w})$ PEO dispersion and electrospun according to the method described above. A $37.5 \%(\mathrm{w} / \mathrm{w})$ solution of ALA was prepared in ultrapure water. $76.8,37.2$, or $12.2 \mathrm{mg}$ of ampicillin per $\mathrm{g}$ of ALA was added to the protein solution to achieve the final ampicillin content in the dry nanofibers of $6 \%, 3 \%$, or $1 \%(w / w)$, respectively. 
Characterization of Protein/Polymer Entanglement by Rheology. A steady state flow test was conducted using an AR-G2 rheometer (TA Instruments, Waters Corporation, Raleigh, NC) equipped with a cone of an angle of $1^{\circ}$ and a diameter of $60 \mathrm{~mm}$. The viscosity was determined at shear rates from 10 to $1000 \mathrm{~s}^{-1}$ at $25{ }^{\circ} \mathrm{C}$ with a 5 min equilibration period prior to each measurement. The tolerance was set to 5\% with a maximum measuring time of $1 \mathrm{~min}$ for each shear rate. Measurements that did not reach equilibrium (5\% deviation) within 1 min were excluded.

Electrospinning of ALA-Based Nanofibers and Cross-Linking. ALA/PEO dispersions were stirred for at least $30 \mathrm{~min}$ prior to electrospinning. The electrospinning was conducted on a horizontal electrospinning setup including a high-voltage generator (ES50P10W, Gamma High Voltage Research, Ormond Beach, FL) and a collector plate covered with aluminum foil. The flow of the dispersion for electrospinning $(1 \mathrm{~mL} / \mathrm{h}, 20 \mathrm{G}$ needle) was controlled by a syringe pump (New Era Pump Systems, Farmingdale, NY). The electrospinning was performed at $15-16 \mathrm{kV}$ at room temperature $(20 \pm 2$ ${ }^{\circ} \mathrm{C}$ ) with a relative humidity of $<30 \%$ with a distance of $15 \mathrm{~cm}$ to the collector plate.

To improve the stability of the nanofibers in aqueous medium, glutaraldehyde (GTA) vapor was used for cross-linking. Nanofibers were placed on a support located above a Petri dish containing $20 \mathrm{~mL}$ of $25 \%(w / w)$ GTA solution in a closed container. An illustration of the setup can be found in the Supporting Information Figure S1. The nanofibers were air-dried for $24 \mathrm{~h}$ under the fume hood to evaporate excess GTA after the cross-linking treatment.

Assessment of Nanofiber Morphology by Scanning Electron Microscopy (SEM). The fibers were visualized by scanning electron microscopy (SEM, Phenome Pro X, Phenom-World, Eindhoven, The Netherlands). The diameter of the fibers was evaluated from at least 15 SEM images taken of each samples by using ImageJ software (National Institutes of Health, Bethesda, MD) with at least 300 size measurements per sample.

Composition Analysis by Fourier Transform Infrared Analysis (FTIR). FTIR analysis was conducted on solid dry samples on a Bomem MB-Series spectrophotometer (Bomem, Quebec, QC, Canada) with an Arid-Zone light source spectrometer based on a universal attenuated total reflectance FTIR sensor equipped with DuraScope diamond ATR (SensIR Technologies, Danbury, CT). Absorbance spectra (an average of 16 scans) were recorded in the range $4000-600 \mathrm{~cm}^{-1}$ with a spectral resolution of $2 \mathrm{~cm}^{-1}$.

Disintegration Test of ALA-Based Nanofibers. The nanofibers were punched into disks of $10 \mathrm{~mm}$ in diameter and immersed in $2 \mathrm{~mL}$ of ultrapure water for $24 \mathrm{~h}$ at room temperature. Hereafter, the disks were dried under air flow for a minimum of $24 \mathrm{~h}$, and the weight loss was determined according to eq 1 :

$$
\text { weight loss }(\%)=\frac{W_{\mathrm{i}}-W_{\mathrm{f}}}{W_{\mathrm{i}}} \times 100 \%
$$

where $W_{\mathrm{i}}$ is the initial weight of the $10 \mathrm{~mm}$ fiber discs and $W_{\mathrm{f}}$ is the final weight of the fiber disks after being immersed in water for $24 \mathrm{~h}$ and dried for a minimum of $24 \mathrm{~h}$.

Protein Structure Determination by Circular Dichroism (CD). ALA/PEO-84 nanofibers were disintegrated in ultrapure water to a final concentration $0.12 \mathrm{mg}$ of nanofibers $/ \mathrm{mL}$, which was equivalent to $0.10 \mathrm{mg} / \mathrm{mL}$ ALA and $0.02 \mathrm{mg} / \mathrm{mL}$ PEO. As controls, $0.1 \mathrm{mg} / \mathrm{mL}$ neat ALA and $0.02 \mathrm{mg} / \mathrm{mL}$ PEO dissolved in ultrapure water were used. Far-UV measurements (190-250 nm) were performed on a Chirascan Applied Photophysics CD spectrometer (Applied Photophysics, Leatherhed, UK) equipped with a water bath temperature control system set at $25{ }^{\circ} \mathrm{C}$. A rectangular $10 \mathrm{~mm}$ path length quartz cuvette (Hellma Analytics, Müllheim, Germany) was used. Spectra were collected with a $0.5 \mathrm{~nm}$ data interval, a $1 \mathrm{~s}$ measuring time per point, and a spectral bandwidth of $1.0 \mathrm{~nm}$. Three scans were recorded and averaged for each sample, which was analyzed in duplicates. The $\mathrm{CD}$ data were smoothed by a 4-point Savitzky-Golay algorithm.

Characterization of Mechanical Properties of Electrospun ALA-Based Nanofibers. The mechanical properties of untreated and GTA cross-linked electrospun ALA-based nanofiber were characterized at room temperature in a TA.XT plus texture analyzer (Stable Micro Systems, Godalming, UK), with a maximum load of 50 $\mathrm{N}$ in the loading cell, a resolution of $1 \mathrm{~N}$, a test speed of $2 \mathrm{~mm} / \mathrm{s}$, and a gripping distance of $20 \mathrm{~mm}$. Rectangular-shaped samples of approximately $35 \times 20 \mathrm{~mm}^{2}$ were cut from the original nanofiber mats and adjusted into the metal grips of the texture analyzer. Stress vs strain curves were obtained, and the slope of the linear part of the curve, corresponding to the elastic behavior, was calculated as Young's modulus. ${ }^{28}$

Biocompatibility of ALA-Based Nanofibers Assessed in Vitro. TR146 (human squamous cell carcinoma, buccal) and NIH 3T3 (murine embryonic fibroblast) cells were cultured in Corning Costar polystyrene culture flasks $\left(175 \mathrm{~cm}^{2}\right.$, Sigma-Aldrich) in DMEM supplemented with L-glutamine $(2 \mathrm{mM})$, penicillin $(100 \mathrm{U} / \mathrm{mL})$, streptomycin $(100 \mu \mathrm{g} / \mathrm{mL})$, and FBS $(10 \%(\mathrm{v} / \mathrm{v}))$ for TR146 cells and NCS $(10 \%(\mathrm{v} / \mathrm{v}))$ for NIH $3 \mathrm{~T} 3$ cells in a humidified incubator at $37{ }^{\circ} \mathrm{C}$ with $5 \% \mathrm{CO}_{2} .100 .000 \mathrm{TR} 146$ cells/well or $50.000 \mathrm{NIH} 3 \mathrm{~T} 3$ cells/well were seeded in flat-bottom, transparent 12-well plates (Thermo Scientific Nunc Nunclon Delta Surface) and cultured for 48 $\mathrm{h}$ under the aforementioned conditions. The cells were washed twice in $2 \mathrm{~mL}$ of warm $10 \mathrm{mM}$ HEPES in HBSS $\mathrm{pH} 7.4$ (hHBSS) prior to exposure to the fibers. Small nanofiber mats of $10 \mathrm{~mm}$ in diameter were placed in $2.5 \mathrm{~mL}$ of hHBSS on top of the cell layer or placed in stainless steel baskets mounted above the cell layer, and the cells were incubated for $4 \mathrm{~h}$ at $37^{\circ} \mathrm{C}$. Short-term exposure was used to avoid cell proliferation and differentiation to influence the results. After treatment, the nanofibers were removed (to the extent possible) and the cells were washed twice in hHBSS pH 7.4, and the cell morphology was visualized under an Eclipse Ti-S microscope (Nikon, Tokyo, Japan). The viability of the cells after exposure was evaluated by the MTS/PMS colorimetric assay. The cells were incubated at 37 ${ }^{\circ} \mathrm{C}$ for $45-120 \mathrm{~min}$ with $1 \mathrm{~mL}$ reagent solution containing $240 \mu \mathrm{g} /$ $\mathrm{mL}$ MTS and $2.4 \mathrm{mg} / \mathrm{mL}$ PMS in hHBSS buffer with mild shaking (50 rpm). Hereafter, $100 \mu \mathrm{L}$ in quintuplicate of the metabolized MTS/PMS solution from each well was transferred to a transparent 96-well plate, and the absorbance was measured at $\lambda=492 \mathrm{~nm}$ in a plate reader (POLARstar OPTIMA, BMG LABTECH, Ortenberg, Germany).

Study of Bacteria Growth Inhibition by ALA-Based Nanofibers. Overnight cultures were prepared by picking a single colony of Escherichia coli BW25113, Pseudomonas aeruginosa PA14, Burkholderia thailandensis E264, Escherichia coli ATCC11303, or Escherichia coli BW25113 carrying an ampicillin resistance cassette from a streak plate, followed by growth of the bacteria in $200 \mathrm{~mL}$ of fresh LB broth in a shaking incubator at $200 \mathrm{rpm}$ and $37^{\circ} \mathrm{C}$ for $17 \mathrm{~h} .200 \mu \mathrm{L}$ of an overnight culture was pipetted onto LB agar plates and spread evenly with an L-spreader before being left to dry at room temperature in a flow hood. Each agar plate was divided into four areas. Because we aimed at developing an approach for eradicating microbes growing on surfaces, i.e., for topical delivery and acting in the immediate proximity of the bacteria, $10 \mathrm{~mm}$ diameter fiber mats containing 0,1 , 3 , or $6 \%(\mathrm{w} / \mathrm{w})$ ampicillin were deposited in the center of each area either immediately after inoculating bacteria on agar (lag phase inhibition), or $2.5 \mathrm{~h}$ after inoculation (exponential phase inhibition), or $17 \mathrm{~h}$ after inoculation (stationary phase inhibition). Plates were incubated at $37^{\circ} \mathrm{C}$ for $24 \mathrm{~h}$ and imaged with a camera every hour for the first $6 \mathrm{~h}$ to follow the formation of the inhibition area. To compare inhibition against different Gram-negative species and for different phases of growth, the inhibition area was calculated relative to the fiber mat area. Each measurement was performed at least in triplicate, with graphs reporting their mean and standard error of the mean.

\section{RESULTS AND DISCUSSION}

Degree of Entanglement of ALA with PEO Depends on ALA Concentration. Several parameters influence the electrospinning process and specifically the morphology of the resulting nanofibers. ${ }^{1}$ The physicochemical properties of the solution to be electrospun can be adjusted to tune the 
production of fibers with specific features. In this regard, the rheological behavior of the solution is crucial for electrospinning and directly related to the intermolecular entanglement between the macromolecules in bulk. ${ }^{29}$ Sufficient entanglement is indeed required to facilitate fiber formation during electrospinning.

To investigate the effect of PEO on the ALA solutions and monitor the molecular interaction between ALA and PEO, a rheological characterization of ALA/PEO mixtures was performed. Names corresponding to the content of ALA in the samples tested are provided in Table 1 . The viscosities of the neat ALA solutions were low even at high protein concentrations (up to $18.75 \%(w / w)$, ALA-84) and overall showed Newtonian behavior (i.e., the viscosity is independent of shear rate)-two properties indicative of limited intermolecular entanglement (Figure 1A, circles). As expected, the neat PEO dispersion was viscous, showed non-Newtonian behavior, and displayed shear thinning properties (Figure 1A, green triangles). Importantly, these properties were maintained
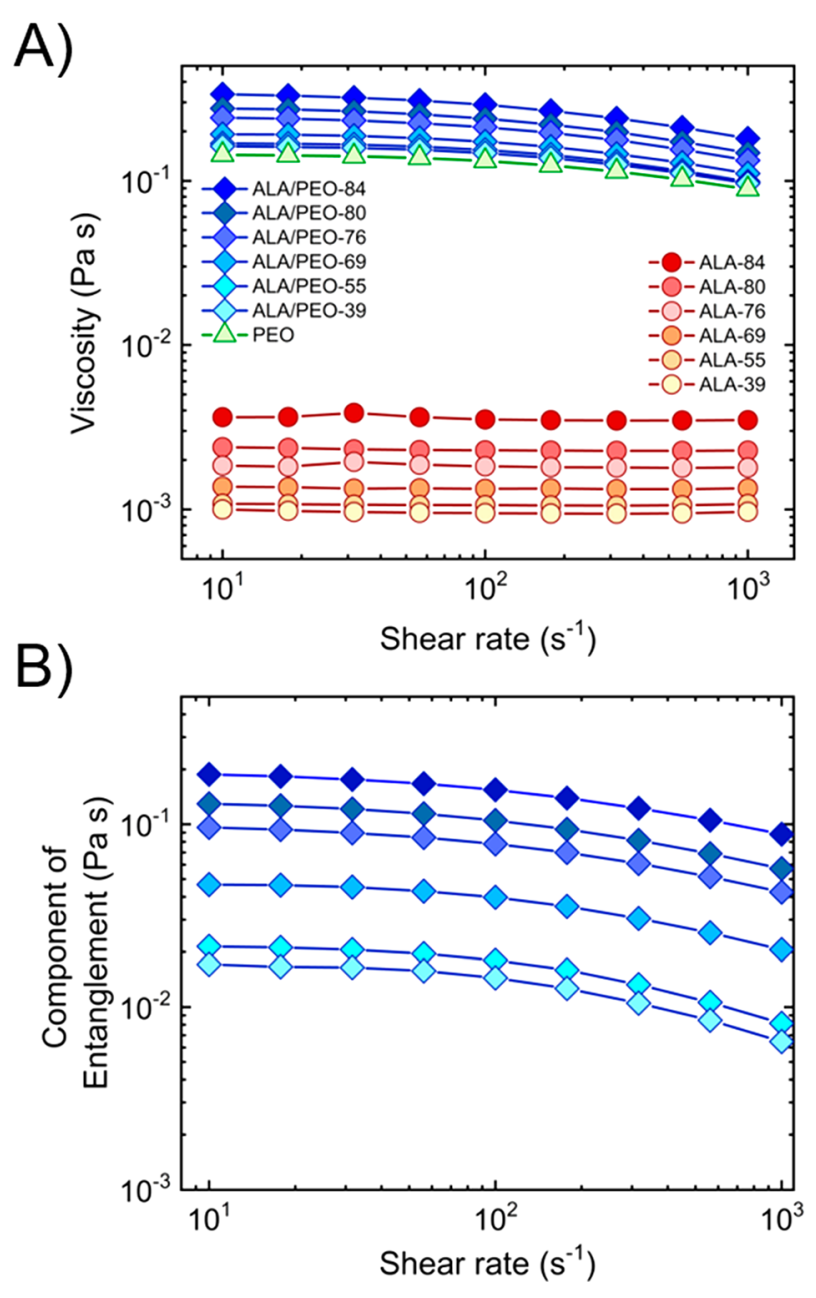

Figure 1. (A) Rheological characterization of neat ALA solution, neat PEO, and ALA/PEO blend dispersions. (B) Component of entanglement for ALA/PEO blend dispersions determined according to Hassen et al. ${ }^{29}$ Curves represent the average viscosity at the given shear rate. $N=2$ and $n=2-3$. $N$ represents the number of samples, and $n$ represents the number of measurements per sample. Data are represented as a mean. Standard deviations were below $5.6 \times 10^{-4}$ and $3.8 \times 10^{-2} \mathrm{~Pa} \cdot \mathrm{s}$ for neat ALA samples and samples containing $\mathrm{PEO}$, respectively. in the ALA/PEO blend dispersions, which all showed clear shear-thinning behavior (Figure 1A, diamonds). It is noticeable that the protein-polymer blend had a significantly higher viscosity than the neat PEO dispersion. Mixing ALA with PEO promoted an expected change in the arrangement of the macromolecules in the bulk through interactions between the polymer and the proteins, which leads to a restriction in the fluid flow and thus an increase in viscosity. According to Hassan et al., ${ }^{29}$ the strength of binding between the protein and the polymer of interest (hereafter named the "component of entanglement") can be assessed by subtracting the viscosity coefficient for the individual components in the dispersion, i.e., ALA and PEO, from the total viscosity coefficient of the blend measured at the same conditions (namely concentration, temperature, and shear rate). The component of entanglement increased with increasing concentrations of ALA and decreased slightly with increasing shear rates, as some of the proteinpolymer entanglement may be broken under shear (Figure 1B). The results clearly indicate that ALA and PEO strongly entangle, which is essential for successful electrospinning of the ALA/PEO blend dispersions.

Native proteins often have limited intermolecular entanglement, and unfolding of the proteins is often necessary to facilitate their electrospinning. ${ }^{30}$ However, the protein bioactivity, which is related to their three-dimensional folding, may significantly be reduced if denaturation occurs. Therefore, it is ideal to maintain the intact native structure of the protein, while increasing the overall viscosity of the solution by other means. An alternative strategy to effectively electrospin proteins in their native form is to blend in a high molecular weight "carrier" polymer to increase the viscosity of the protein solution and hereby facilitate the electrospinning of the protein. ${ }^{31}$ PEO is a water-soluble and biocompatible synthetic polymer with excellent ability to be electrospun ${ }^{6}$ and furthermore favorably interacts with ALA (Figure 1B). For these reasons, PEO was chosen as a "carrier polymer" to facilitate the electrospinning of ALA.

ALA Content Determines Nanofiber Morphology and Size. The morphology and diameter of electrospun nanofibers are very important for their functionality and biological performance. $^{32,33}$ It was not possible to produce fibers without PEO due to a low degree of intermolecular entanglement and hence low viscosity of the neat ALA solutions. The degree of entanglement is a critical parameter for the formation of nanofibers without artifacts (e.g., beading), and the viscosity and degree of entanglement with PEO were highly dependent on the ALA concentration (Figure 1). Accordingly, the formation of the protein-based nanofibers was expected to be highly dependent on the ALA to PEO w/w ratio. Nanofibers of neat PEO electrospun from $3.7 \%(\mathrm{w} / \mathrm{w})$ PEO in water were extensively beaded (Figure 2). The presence of beads is often considered as a sign of poor quality of the nanofibers, leading to a high heterogeneity of the material. Fibers with a significant presence of beads at a low ALA concentration were also observed (Figure 2A, top). By increasing the concentration of ALA, the bead formation diminished, and at an ALA content of $76 \%(\mathrm{w} / \mathrm{w})$ (ALA/PEO-76) thin uniform fibers were produced (Figure 2A, bottom). The entanglement of polymer with protein is a central driving force for high quality fiber production. ALA/PEO-39 and ALA/PEO-55, which form beaded fibers, have a similar component of entanglement, which is $\sim 10$ times lower than the component of entanglement for ALA/PEO-76, which forms beadless fibers (Figure 1B). 

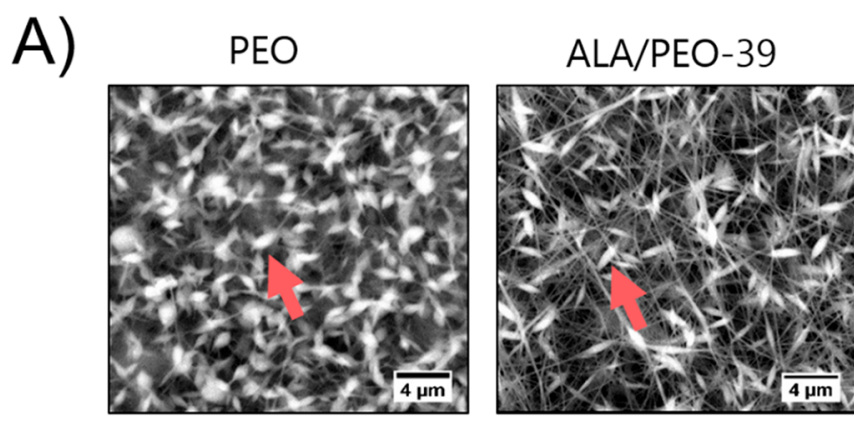
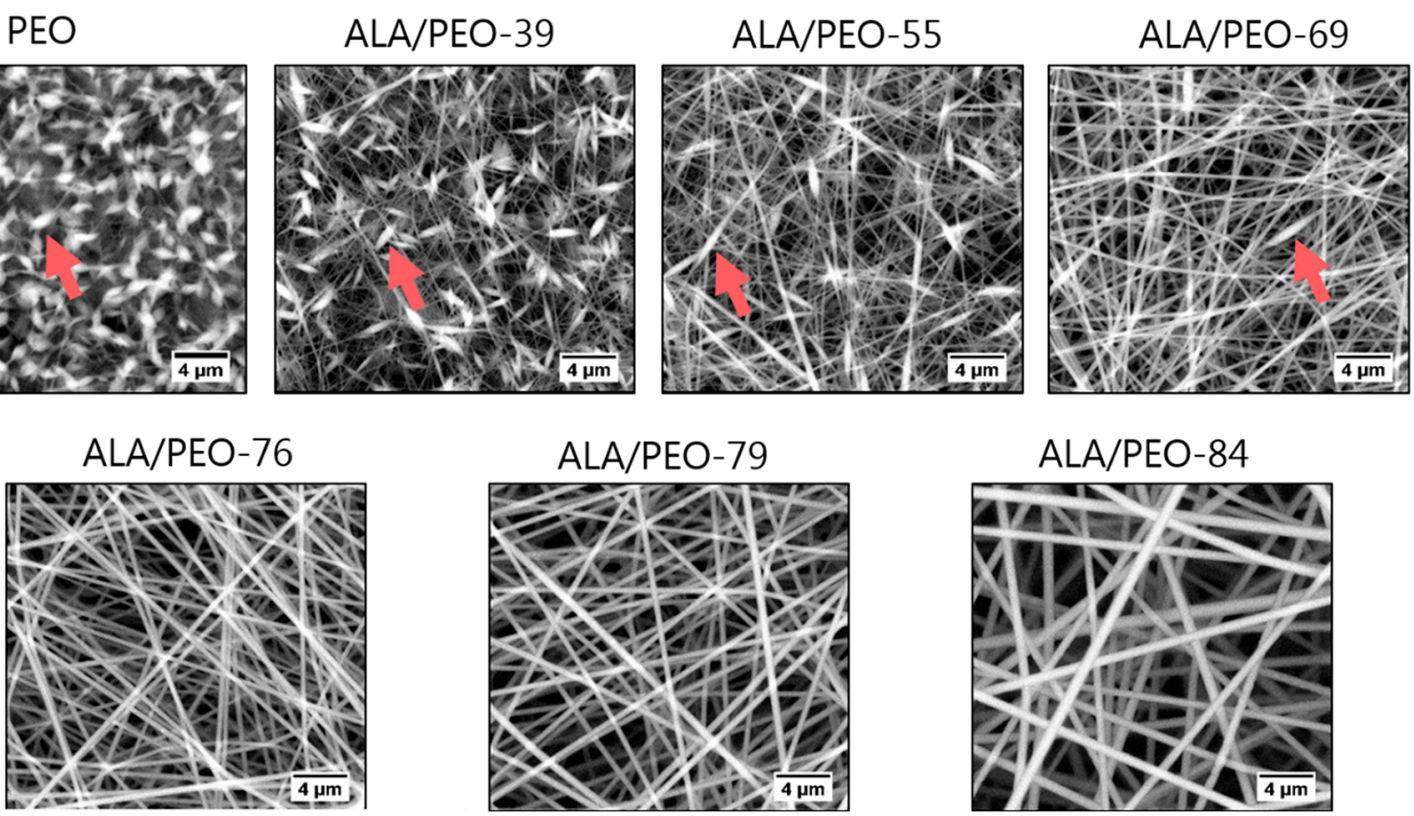

B)
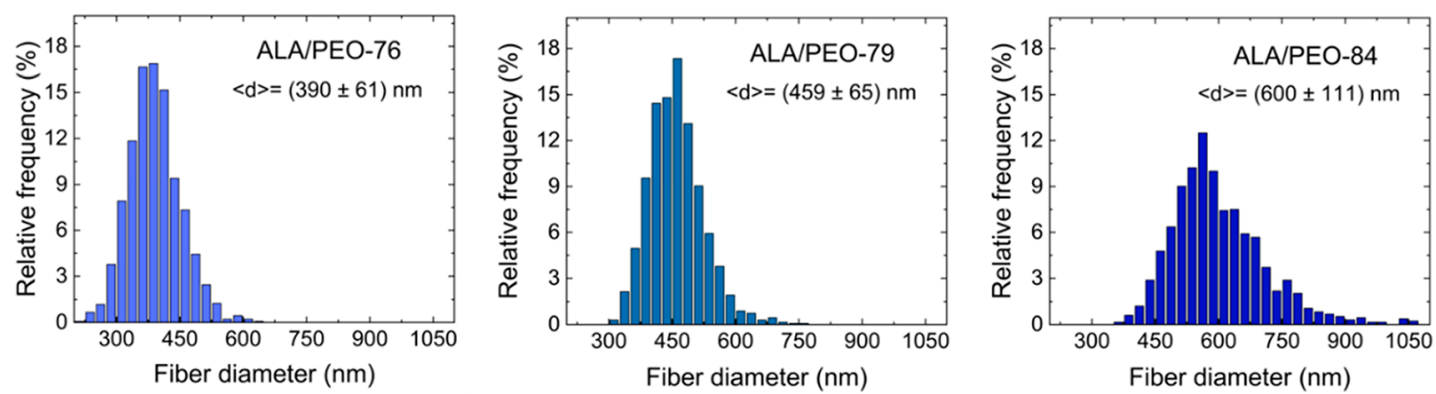

Figure 2. (A) Scanning electron micrographs of nanofibers produced by electrospinning of ALA and PEO. Red arrows indicate beading. Magnification: 10000X. (B) Size distributions of electrospun ALA/PEO nanofibers without beading (i.e., ALA/PEO-76, -79, and -84) and of increasing ALA content. The average fiber diameter is provided with standard deviations. $N=3$ and $n>300$. $N$ is the number of samples, and $n$ is the number of fibers measured.

Thus, a good correlation between the degree of entanglement and the quality of the electrospun fibers was observed, and it shows that the formation of beadless fibers can be predicted by the absolute increase in viscosity due to interactions between ALA and PEO.

The average diameter of the electrospun nanofibers increased with increasing ALA concentration as can be qualitatively seen from the SEM images (Figure 2A, bottom) and from the diameter analysis (Figure 2B). Even small changes in the concentration of ALA induced significant differences in the diameter of the nanofibers. Indeed, changing the protein content in the nanofibers from $76 \%(\mathrm{w} / \mathrm{w})$ (ALA/ $\mathrm{PEO}-76)$ to $84 \%(\mathrm{w} / \mathrm{w})(\mathrm{ALA} / \mathrm{PEO}-84)$ resulted in an increase in the average fiber diameter from $390 \pm 61$ to 600 $\pm 111 \mathrm{~nm}$, demonstrating the excellent size tunability of the ALA-based fibers with high protein content. In this size range, nanofibers systems present a quite high efficiency as delivery system as shown, e.g., by the fast release of the anticancer drug paclitaxel from poly(lactic-co-glycolic acid) (PLGA) nanofibers $(770 \pm 13 \mathrm{~nm})$ when compared to micrometer sized $(2.5 \pm$ $0.32 \mu \mathrm{m})$ PLGA fibers. ${ }^{32}$ Similarly, Chen et al. also showed that the release of 5-fluorouracil from poly(lactic acid) fibers was higher for fibers with a smaller diameter $(0.35 \pm 0.11 \mu \mathrm{m})$ compared to larger diameter $(1.02 \pm 0.37 \mu \mathrm{m}){ }^{39}$ In the context of tissue engineering, the size of the nanofibers also affects their interaction with cells. ${ }^{34}$ For example, fibers with larger diameters $(600 \pm 110 \mathrm{~nm})$ allowed deeper migration into the scaffold of osteoblastic cells after longer cultivation. ${ }^{34}$ In contrast, thinner nanofibers $(110 \pm 40 \mathrm{~nm})$ showed improved cell differentiation. ${ }^{34}$ As a consequence, the possibility of modulating the fiber diameter is crucial for tailoring the nanofiber-based platform to the desired biological response.

Globular proteins such as ALA fold into three-dimensional structures, carry multiple charges on their surfaces and may expose hydrophobic pockets. This also makes such globular proteins especially versatile for encapsulation of hydrophobic, polar, and ionic drugs. Specifically, ALA has been shown to interact with ions, other proteins, and lipid membranes. ${ }^{35,36}$ We speculate whether ALA could potentially be used as a tunable platform to carry other bioactive macromolecules such as polymeric carbohydrates, lipids, natural oils, or other proteins and hereby produce natural biocompatible nanofibers with specific functional or biological properties. For example, electrospun nanofibers of high ALA content in complex with oleic acid could be an improved formulation of HAMLET/ BAMLET in the form of biocompatible and bioactive nanofibers for the treatment of cancers.

ALA-Based Nanofibers with Excellent Water Stability Were Produced by Cross-Linking with GTA. Both fast- 
A)
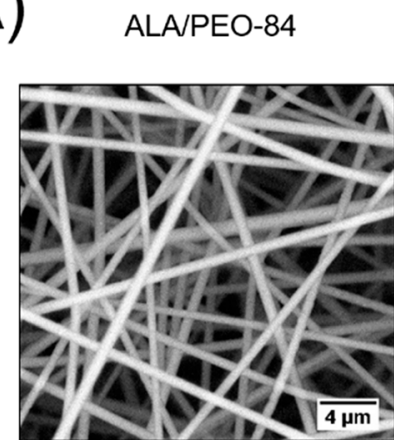

ALA/PEO-84 GTA 24 hours

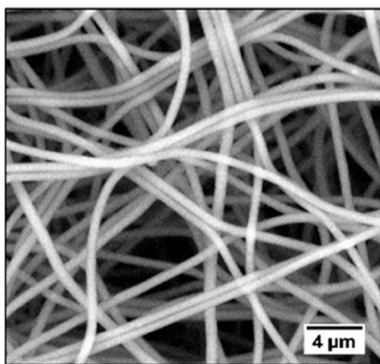

ALA/PEO-84 GTA 24 hours after exposure to water

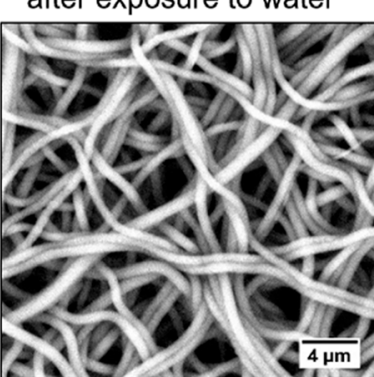

B)

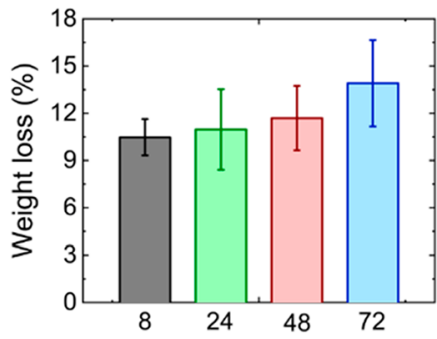

GTA treatment time (hours)

Figure 3. (A) Scanning electron micrographs of nontreated (ALA/PEO-84), cross-linked (GTA vapor, $24 \mathrm{~h}$ ), and cross-linked (GTA vapor, $24 \mathrm{~h}$ ) ALA/PEO-84 nanofibers after exposure to water for $24 \mathrm{~h}$. Magnification: 10000×. (B) Weight loss of ALA/PEO-84 nanofibers after exposure to water for $24 \mathrm{~h} . N=2$ and $n=3$, where $N$ is the number of samples and $n$ is the number of measurements per sample. Error bars represent standard deviations.

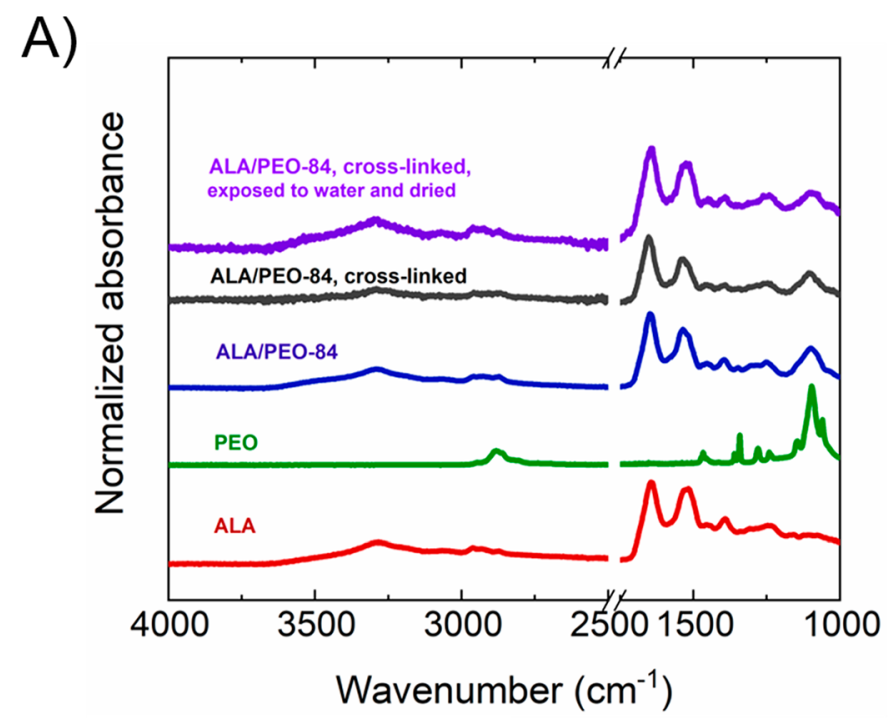

B)

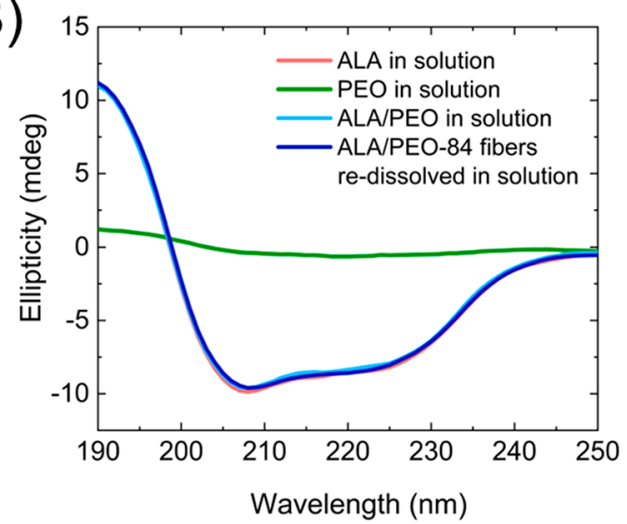

C)

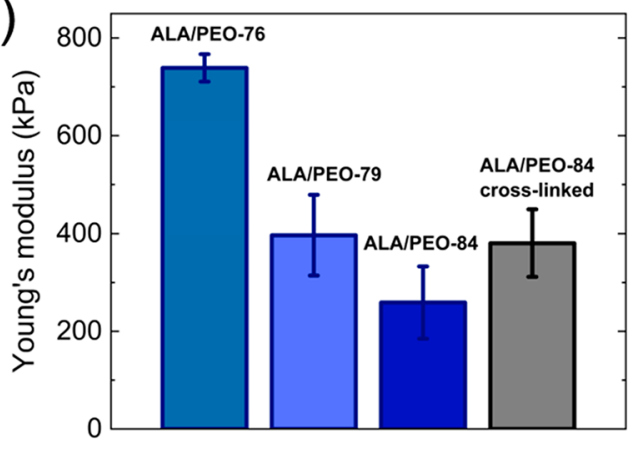

Figure 4. (A) Representative FTIR absorbance spectra of neat PEO, neat ALA, nontreated fibers, and ALA-based fibers cross-linked with GTA vapor $\left(24 \mathrm{~h}\right.$ ). The ATR crystal absorbs around $2000 \mathrm{~cm}^{-1}$, and these data points are excluded. $N=3$. (B) Representative CD spectra of neat ALA, neat PEO, ALA and PEO mixture, and ALA and PEO released from electrospun ALA/PEO-84 nanofibers. $N=2$ and $n=2$. (C) Young's modulus of electrospun ALA/PEO-76, -79, and -84 nanofibers as well as cross-linked ALA/PEO-84 nanofibers. $N=2$ and $n=3 ; N$ represents the number of samples, and $n$ is the number of measurements per sample. Error bars are standard deviations.

dissolving and dosage forms with higher integrity in water have applications in drug delivery. As expected, the hydrophilicity of both ALA and PEO leads to ALA/PEO electrospun fibers that instantly disintegrated when exposed to an aqueous medium. This property is advantageous for some applications but may represent a limiting step for the effective use of the material in other cases. GTA has been used as an affordable and effective protein cross-linking agent for several protein-based nanofibers consisting of e.g. collagen and gelatin. ${ }^{37,38}$ To increase the stability of the ALA/PEO fibers, a cross-linking treatment with 
GTA vapor was performed. An illustration of the setup is presented in Figure S1. GTA vapor was used to limit the amount of adsorbed GTA in the nanofibers that may result in a reduced biocompatibility of the fibers. ${ }^{38}$ After treatment of the fibers with GTA vapor, a color shift from white to yellow was observed. This is indicative of the formation of aldimine bonds $(\mathrm{CH}=\mathrm{N})$ between the free amino groups of ALA and aldehyde groups of GTA, as previously observed. ${ }^{37,38}$ Nanofibers conserved their nanofibrous morphology but seemed more intertwined and bended following cross-linking (Figure $3 \mathrm{~A})$.

This rearrangement of the fibers within the mat significantly changes their stability in water. The nanofibers were immerged in water for $24 \mathrm{~h}$, and the weight loss was determined. Already after $8 \mathrm{~h}$ of exposure to GTA vapor and in sharp contrast to the fast-dissolving non-cross-linked ALA/PEO nanofibers, the ALA/PEO fibers did not macroscopically disintegrate, proving a significantly increased stability of the fibers in aqueous solution. Exposure to GTA for more than $8 \mathrm{~h}$ did not provide a significant increase in nanofibers stability with a weight loss in the range of $10-12 \%$ (Figure $3 \mathrm{~B}$ ). Moreover, immersion of ALA/PEO fibers in water did not change the morphology of the individual fibers, but the fibrous network appeared even more intertwined (Figure 3A). This could be related to partial dissolution after immersion in water due to the presence of non-cross-linked PEO as reported by others. ${ }^{10}$ Cross-linking the ALA-based nanofibers by heat was also explored by incubating the ALA-based nanofibers at $90{ }^{\circ} \mathrm{C}$ for $8-24 \mathrm{~h}$ (Figure S2). This treatment increased the stability of the ALAbased nanofibers to the same extent as the treatment of the nanofibers with GTA vapor. However, subsequent visualization of the fibers revealed significant loss of their fibrous structure (Figure S2). Cross-linking of neat PEO nanofibers by heat at $80{ }^{\circ} \mathrm{C}$ was reported to form a coherent PEO film with no fiber structure. ${ }^{10}$ Melting of PEO in the ALA-based nanofibers most likely explains the loss of structure. The fibrous structure is of great importance for the biological performance of the nanofibers. The use of heat for cross-linking the ALA-based nanofibers was not explored further due to the superior ability of GTA vapor to not only cross-link but also retain the structure of the nanofibers after cross-linking.

Figure 3 shows that both highly soluble and also "water stable" nanofibers can be produced from the same ALA-based platform. This significantly broadens the number of potential medical applications for which the use of ALA/PEO nanofibers could be explored further. Highly water-soluble electrospun nanofibers could be an alternative dosage form to the fastdissolving films and tablets for a fast onset of action, which can increase the drug bioavailability by fast and local drug release. ${ }^{39}$ These can be administrated with little or no water, which is beneficial for patients with swallowing difficulties. ${ }^{39}$ For example, fast dissolving tables with paracetamol (amoung others Pinex Smelt) or Olazapine (trade name Zyprexa) have been marketed by Teva and Eli Lilly as analgesics and antipsycotic agents, respectively. Oral ultrafast-dissolving drug delivery systems have been also developed by using electrospun ultrafine poly(vinyl alcohol) (PVA) nanofibers; caffeine with high water solubility and riboflavin with poor solubility were assessed as model drugs. ${ }^{40}$ In contrast, for sustained drug release increased stability of the nanofibers in aqueous solution is required. For example, multilayered gelatin nanofibers partially cross-linked with GTA was shown to exhibit sustained zero-order drug release with almost complete elimination of the initial burst release. ${ }^{41}$ In tissue engineering, cross-linking of protein nanofibers to retain the fibrous structure is often necessary for the fibers to act as a scaffold to facilitate cell migration and differentiation. ${ }^{34}$

ALA Content and Cross-Linking Affect the Mechanical Properties of ALA-Based Nanofibers. To verify the composition of the produced nanofibers, FTIR spectroscopy analysis was conducted (Figure 4A). Distinct regions in the FTIR spectra could be identified. ALA in powder form showed peaks at approximately 3280 and $1643 \mathrm{~cm}^{-1}$ representing the vibrational stretching of $\mathrm{N}-\mathrm{H}$ and $\mathrm{C}=\mathrm{O}$, respectively. $\mathrm{PEO}$ is characterized by $\mathrm{C}-\mathrm{H}_{2}$ stretching around $2900 \mathrm{~cm}^{-1}$ and $\mathrm{C}-$ $\mathrm{O}-\mathrm{H}$ stretching at $1100 / 958 \mathrm{~cm}^{-1}$. The FTIR absorbance spectrum of the fibers confirms the simultaneous presence of these peaks, which indicate that ALA and PEO coexist in the fiber structure. Furthermore, no significant differences in the FTIR absorbance spectrum were observed after cross-linking with GTA, and the GTA-treated ALA/PEO nanofibers did not show evident structural differences even after incubation in water for $24 \mathrm{~h}$. This indicates that both ALA and PEO are cross-linked into the nanofiber matrix, which demonstrates once more the efficacy of the GTA cross-linking process.

The CD spectrum of native ALA (Figure 4B) shows characteristic minima at 208 and $212-225 \mathrm{~nm}$ indicative of an $\alpha$-helical structure of the protein in water. The presence of PEO did not affect the secondary structure of ALA (Figure 4B). Importantly, ALA retained its native structure after electrospinning and subsequent release after dissolution of ALA/PEO-84 nanofibers in water (Figure 4B). The importance of ALA as a nutrient should not be underestimated. $^{13-19}$ As ALA retains its native structure after electrospinning, nanofibers of ALA could be an alternative solid form of the milk protein with beneficial nutritional value. For example, protein nanofibers have been proposed as carriers of flavors or nutraceuticals. ${ }^{10}$ Electrospun nanofibers have also been suggested as potential texture modifiers in food, ${ }^{10}$ and having intact ALA in the form of tunable nanofibers would clearly offer a broader range of potential applications. Biologics, e.g., proteins, are the fastest growing class of pharmaceutics due to their high specificity and potency but often have low physicochemical stability, which poses a great challenge in their formulation and storage. ${ }^{42}$ Electrospinning may be an alternative to the conventional techniques such as freeze-drying and spray-drying to produce a new solid form, which can retain the native structure and the bioactivity of the protein. $^{42}$

The mechanical properties of the nanofibers are also important parameters that can have a significant effect on their biological performance. The results presented in Figure $4 \mathrm{C}$ show that the mechanical properties of ALA/PEO can be modulated. The Young's modulus of the nanofibers significantly depended on ALA content with the stiffness of the fiber material decreasing with increasing ALA content (Figure 4C). This could indicate that a higher PEO to ALA ratio in the fibers improves their mechanical properties, which make them more resistant to mechanical stress.

Improving the mechanical performance of nanofibers after GTA-cross-linking has been widely reported in the literature. $^{43-45}$ Specifically, the modulus of starch or gelatin fibers increased 9-fold and almost 10-fold, respectively. The stiffness of the ALA-based nanofibers increased after cross-linking by exposure to a GTA vapor for $24 \mathrm{~h}$ (Figure 4C). This is not surprising as enhanced bonding and intersection points are 
A)

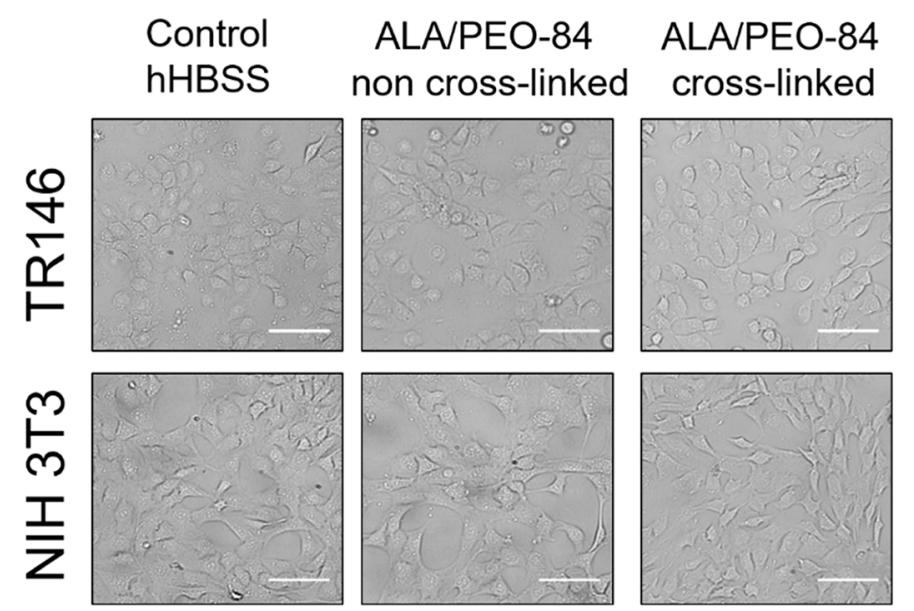

B)

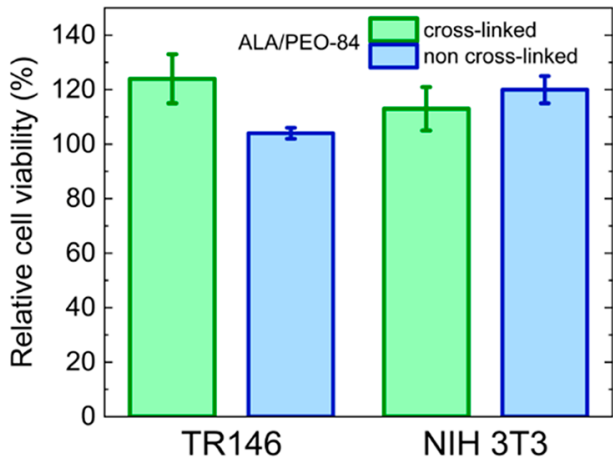

Figure 5. (A) Bright-field microscopy images of TR146 and NIH 3T3 cell monolayers exposed for $4 \mathrm{~h}$ to ALA/PEO-84 nanofibers nontreated and cross-linked by GTA vapor $(24 \mathrm{~h})$. Cross-linked ALA/PEO-84 nanofibers were placed in baskets above the cells. All images were acquired at $40 \times$ magnification. Scale bar $100 \mu \mathrm{m}$. (B) Relative cell viability of TR146 and NIH 3T3 cell monolayers exposed for $4 \mathrm{~h}$ to nontreated and cross-linked ALA/PEO-84 nanofibers. Results are presented as the relative cell viability (\%) compared to the control (hHBSS, $10 \mathrm{mM} \mathrm{HEPES} \mathrm{in} \mathrm{HBSS} \mathrm{pH}$ 7.4). Error bars are standard error of mean. $N=2$ and $n=3 ; N$ represents the number of cell passages, and $n$ is the number of samples.

induced by the GTA treatment, which create a more robust interfiber web (Figure 3A). ${ }^{43}$ Furthermore, this tensile strength study was consistent with visual and tactile examination of the fibers: decreased ALA content fibers resulted in less flexible and easily breakable fibers, while GTA-cross-linking enhanced the stiffness of the fiber material. Altogether, these data show that the mechanical properties of the ALA/PEO nanofibers can be finely modulated both by changing the parameters of the electrospun solution and via postproduction treatment by GTA. Wingate et al. have demonstrated that differentiation of mesenchymal stem cells can be modulated by differences in the elasticity of the nanofiber-based scaffold. ${ }^{46}$ This was proposed as a new tool for tuning vascular tissue regeneration. ${ }^{46}$ Nanofibers are especially suitable for topical administration for e.g. wound healing or transdermal drug delivery. ${ }^{3}$ In general, a reduction in stiffness and thus an increased flexibility can make the material more easily adaptable to curved surfaces of the human body, e.g., in the oral cavity or certain areas where the skin stretches and contracts such as in joints. Thus, the mechanical properties of the ALA-based nanofiber could potentially be adapted to the biological purpose by small changes in ALA concentration or by cross-linking.

ALA-Based Nanofibers Display Good Biocompatibility in Vitro. ALA, as a whey protein, is biocompatible and biodegradable, ${ }^{11}$ which makes it an appropriate macromolecule to consider for biomedical purposes. PEO is classified as an "Inactive Ingredient" by the FDA (FDA UNII 16P9295IIL). To evaluate the biocompatibility of the electrospun ALA-based nanofibers, cultured cell monolayers from the TR146 (human buccal epithelium) and NIH 3T3 (murine fibroblast) cell lines were exposed to nontreated and cross-liked ALA-based nanofibers for $4 \mathrm{~h}$ (Figure 5). A few areas of cells were affected by the free-floating cross-linked ALA-based nanofibers and showed changes in cell morphology, e.g., cell rounding. This happened only if the fibers were in contact with the cells, and it did not affect the overall viability of the cells. To exclude contact-dependent changes due to the physical contact of fibers with the cell monolayer as reported by others, ${ }^{47}$ the cross-linked nanofibers were placed in baskets above the cell monolayer (i.e., exposure of the cell to the fibers, but not in direct contact; see the Materials and Methods section). As the non-cross-linked fibers dissolved instantly when exposed to an aqueous medium, placing these fiber disks in baskets was not necessary. Exposure of TR146 and NIH 3T3 cell monolayers to the ALA-based nanofibers did not induce changes in the cell morphology or in the cellular viability compared to the control (Figure 5A). GTA is widely used in the medical field as a disinfectant for surgical instruments and has been formulated as a treatment for warts (brand name Glutarol, 10\% GTA (w/ v)). Upon exposure, GTA can cause irritation of the eyes, skin, and respiratory tract and in higher doses induce acute toxicity. The nanofibers were only exposed to minute amounts of GTA by cross-linking the nanofiber in GTA vapor and not by submerging the fibers in GTA solution. The fibers were not washed prior to exposure to the cells in the biocompatibility assay. Accordingly, data in Figure 5B show that the treatment (GTA vapor) used to improve the aqueous stability of the fiber material did not affect its compatibility toward the cell models tested. Because of the good biocompatibility of both ALA and $\mathrm{PEO}$, it was not surprising that the ALA-based nanofibers displayed no toxicity. In the context of clean and environmentfriendly production of biomaterials, ${ }^{4}$ it should be noted that the ALA-based nanofibers were electrospun in water as a solvent, which makes the setup simple and circumvents the need for organic toxic solvents, which are often used to aid the electrospinning process. ${ }^{1}$ This fully waterborne fabrication method represents a great advantage compared to traditional electrospinning of polymers in strong acids and/or toxic solvent systems. ${ }^{4}$ It makes our materials appealing as a safe and biocompatible platform with potential application in medical fields such as tissue engineering and drug delivery.

Evaluation of the ALA-Based Nanofibers as a Potential Drug Delivery System. To demonstrate the potential application of ALA-based nanofibers as a drug delivery system, ALA/PEO-84 nanofibers were loaded with ampicillin by including the antibiotic in the electrospun ALA/ PEO dope, and the fibers were hereafter cross-linked with GTA. No significant changes in neither fiber morphology nor 
A)

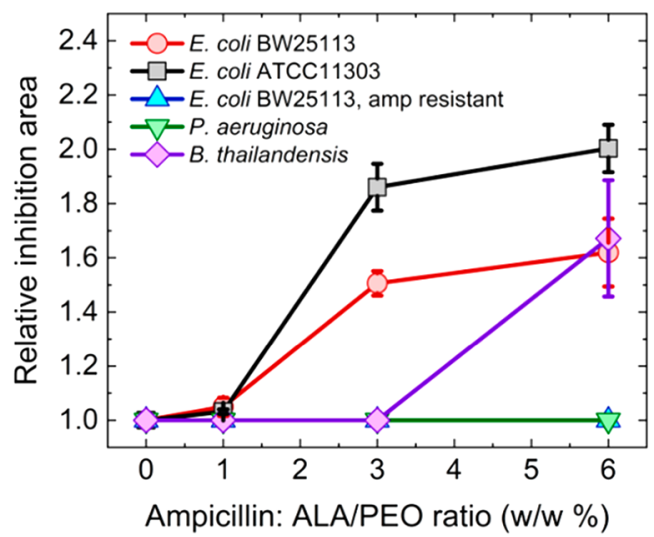

C)

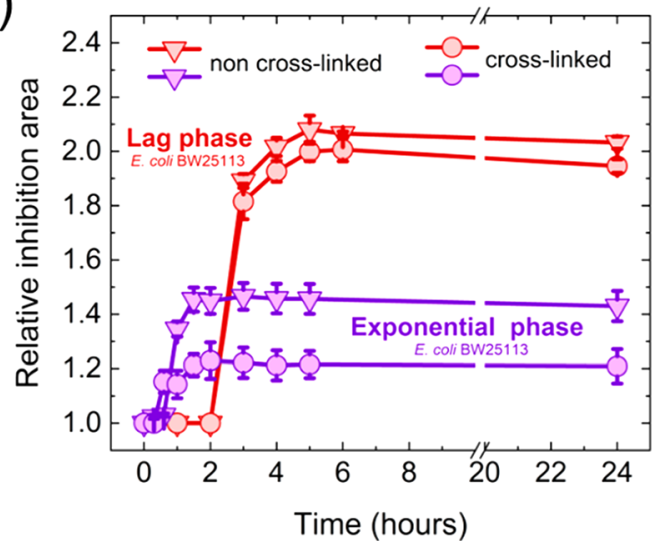

B)

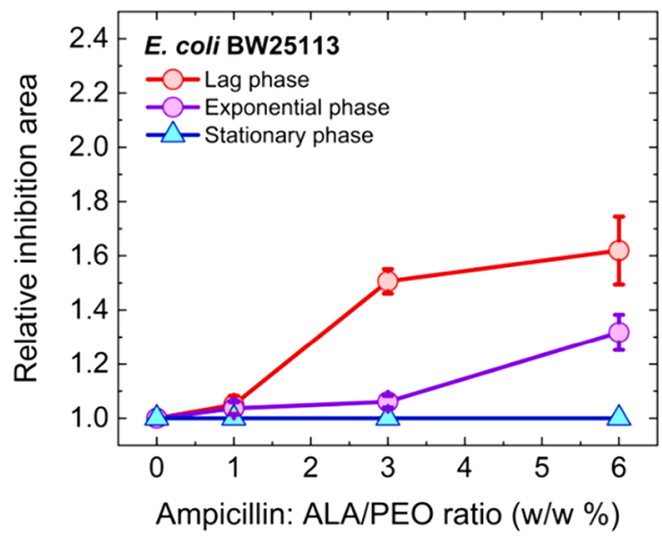

D)

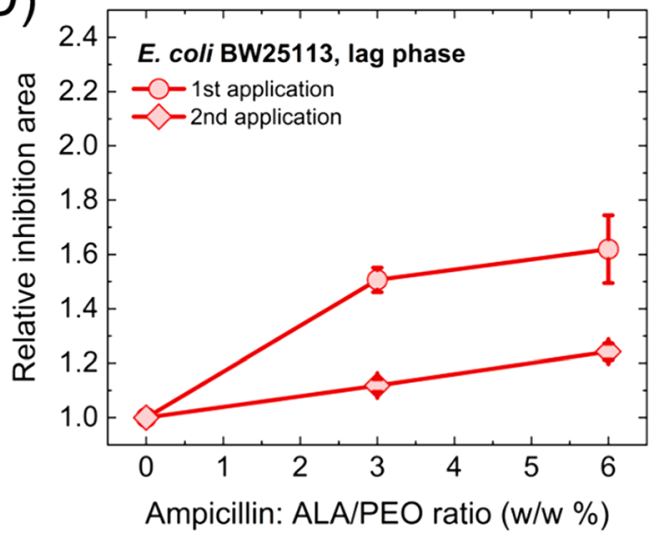

Figure 6. (A) Zone of inhibition antibacterial testing of cross-linked ALA/PEO-84 nanofiber mats loaded with ampicillin (amp) against various Gram-negative bacterial strains in the lag phase of growth and (B) against E. coli BW25113 in different phases of growth. (C) Zone of inhibition antibacterial testing of nontreated and cross-linked ALA/PEO-84 nanofibers loaded with $6 \%(\mathrm{w} / \mathrm{w})$ ampicillin against E. coli BW25113 in the lag phase and in the exponential phase of growth, visualized over time. (D) Zone of inhibition antibacterial testing of cross-linked ALA/PEO-84 nanofibers loaded with $6 \%(\mathrm{w} / \mathrm{w})$ ampicillin against E. coli BW25113 in the lag phase after first and second applications of the same fiber mat on two successive bacteria lawns. Error bars are standard error of the mean. $N \geq 3$, where $N$ represents the number of individual samples.

fiber diameter were found in the presence of ampicillin (Figure S3A). As a proof of concept, inhibition of bacterial growth by a zone-inhibition assay was used as a semiquantitative measurement of ampicillin release from the nanofibers. Ampicillin is on the World Health Organization's List of Essential Medicines being used to treat infections by both Gram-positive and Gram-negative bacteria including the bacteria strains introduced below. In this study, we focused on inhibition of Gramnegative bacteria since these are intrinsically more resistant to antibiotics and thus more challenging to treat. ${ }^{48}$ Specifically, E. coli was chosen as a model organism for Gram-negatives, $P$. aeruginosa is a clinically relevant ESKAPE pathogen, and $B$. thailandensis was chosen as a surrogate for the biological warfare agent B. pseudomallei. Furthermore, the inhibition of E. coli in different phases of growth was investigated, as it has been found that different phases of growth can require different antibiotic therapies. ${ }^{49,50}$

To compare the antibiotic efficacy against different bacterial species, ampicillin-loaded fiber mats with a fixed surface area (round discs of $10 \mathrm{~mm}$ in diameter) were placed on LB agar plates immediately after inoculating with bacteria taken from overnight cultures of E. coli, B. thailandensis, or P. aeruginosa. After $24 \mathrm{~h}$ incubation at $37^{\circ} \mathrm{C}$, the growth of E. coli BW25113 and E. coli ATCC11303 was inhibited with an ampicillin content as low as $1 \%(\mathrm{w} / \mathrm{w})$ in the fibers (squares and circles, Figure 6A). The relative inhibition area correlated well with the ampicillin content, with saturation observed above 3\% (w/ w) for which the relative inhibition area was approximately 1.5 and 1.9 for the E. coli strains BW25113 and ATCC11303, respectively. As negative control, mats of ALA/PEO-84 fibers without ampicillin had no inhibitory effect on any of the strains tested. In addition, ampicillin-loaded ALA/PEO-84 fibers showed no inhibition of an E. coli BW25113 carrying a plasmid encoding an ampicillin resistant cassette (blue triangles, Figure 6A) and of $P$. aeruginosa (green triangles Figure 6A) in line with previously reported findings. Only fibers loaded with $6 \%(\mathrm{w} / \mathrm{w})$ ampicillin produced inhibition zones against $B$. thailandensis comparable to those measured against E. coli (diamonds, Figure 6A). Overall, these results clearly demonstrate the ability of the ALA-based nanofibers to encapsulate and preserve ampicillin.

The capability of the ampicillin-loaded ALA-based fiber mats to inhibit E. coli BW25113 in its different phases of growth was evaluated. The fibers showed reduced inhibition of exponentially growing bacteria (purple, Figure 6B) compared to bacteria in the lag phase (red, Figure 6B). Specifically, ALAbased nanofiber mats loaded with $3 \%$ and $6 \%(\mathrm{w} / \mathrm{w})$ ampicillin showed a reduction in relative inhibition area of a factor of 1.4 
and 1.2 , respectively, when used against exponentially growing bacteria compared to bacteria in the lag phase. Ampicillinloaded ALA-based nanofibers did not show any inhibitory activity against E. coli BW25113 in the stationary phase (blue, Figure $6 \mathrm{~B})$. This is in accordance with previously reported data. ${ }^{49,50}$

The release of ampicillin and hence the inhibited bacterial growth in the presence of antibiotic-loaded nanofibers were expected to be dependent on their aqueous stability. The abrupt increase in the relative inhibition area after $2 \mathrm{~h}$ for bacteria treated in the lag phase correlates with the time needed for E. coli BW25113 to populate the LB agar plates (Figure 6C and Figure S3). When applied to E. coli BW25113 in the lag phase, cross-linked (GTA vapor for $24 \mathrm{~h}$ ) and noncross-linked fiber mats showed very similar inhibition kinetics (red symbols, Figure 6C). In contrast, when applied to E. coli BW25113 in the exponential phase, non-cross-linked fibers generated an increase in the relative inhibition area as quick as 20 min postapplication, thus twice as fast as cross-linked ALAbased fibers (purple symbols, Figure 6C). Moreover, the crosslinked mats had an overall higher inhibition capability $2 \mathrm{~h}$ postapplication, with a relative inhibition area increase of a factor of 1.2 with respect to cross-linked fibers. Furthermore, non-cross-linked fibers dissolved on the LB agar within $20 \mathrm{~min}$ postapplication. Overall, these data demonstrate the versatility of our approach and how the mechanical properties of the ALA-based fiber mats can affect the antibiotic release time scale depending on the specific application.

Finally, in this setup, the possibility of using the same fiber mat to treat multiple bacterial lawns in series was tested. Fiber mats were first applied on a bacterial lawn in the lag phase and $3.5 \mathrm{~h}$ after application. When inhibition had leveled off (circles, Figure 6D), the fiber mats were transferred to a second bacterial lawn, also in the lag phase, on a different LB agar plate. Noteworthy, mats loaded with $6 \%(\mathrm{w} / \mathrm{w})$ ampicillin were able to inhibit the second bacterial lawn with a relative inhibition zone reduced of a factor 1.3 with respect to that measured on the first bacterial lawn (diamonds, Figure 6D). In comparison, mats loaded with $3 \%(\mathrm{w} / \mathrm{w})$ ampicillin showed a significantly lower effect on the second bacterial lawns (diamonds, Figure 6D). Importantly, after removal of the mats from the initial treated culture on LB agar, no bacterial regrowth were observed in the inhibition zone within $24 \mathrm{~h}$, indicating not only inhibition but also killing of the bacteria.

Taken together, these data unambiguously demonstrate that ampicillin-loaded ALA-based fiber mats prepared by electrospinning successfully inhibit the growth of Gram-negative bacteria in vitro in a concentration- and time-dependent manner. The fact that no bacterial regrowth was observed after removal of the nanofiber mats suggests that this treatment is capable to clear eventual persisters to ampicillin at least under in vitro conditions. This capability needs to be further investigated with single-bacterium resolution ${ }^{51}$ by loading ALA-based fibers with antibiotics effective against the stationary phase of Gram-negative bacteria, which is the phase exhibiting the highest persister ratio. ${ }^{49,50}$

\section{CONCLUSIONS}

Based on the favorable properties of neat ALA as a natural carrier and the benefits of a well-controlled processing method such as electrospinning, our findings offer a robust and highly tunable platform for developing novel DDSs. We provide a sustainable and environmentally friendly platform for produc- tion of highly tunable and biocompatible nanofibers obtained by electrospinning of an aqueous solution containing the isolated milk protein ALA. We demonstrate the possibility to produce nanofibers with a content of ALA up to $84 \%(\mathrm{w} / \mathrm{w})$, while using only a small amount of PEO as a carrier polymer and importantly avoiding the use of any toxic solvents. The nanofibers possess high tunability in terms of fiber diameter and mechanical properties by varying the ALA concentration. Cross-linking (either physically or chemically) of the nanofibers gives the possibility to produce protein nanofibers ranging from fast-dissolving and highly flexible networks to more insoluble solid forms. The produced nanofiber-based materials showed good cell culture compatibility and are capable of encapsulating functional ampicillin. Indeed, when tested against Gram-negative bacteria, ampicillin-loaded nanofibers showed an extraordinary efficiency in inhibiting Gram negative bacterial growth in vitro. The degree of bacterial inhibition depended on both the specific growth phase of the bacteria culture and the degree of cross-linking of the ampicillin-loaded nanofibers, demonstrating how the tunability of the system affects the drug delivery properties. Importantly, after removal of the nanofibers, we do not observe bacterial regrowth, suggesting that this treatment is capable to clear eventual persisters to ampicillin under in vitro conditions. This can pave the way for addressing one of the most critical challenges in medical sciences related to the dramatic increase of bacteria resistance toward standard antibiotics treatment. Finally, ALA has a number of extraordinary properties as a nutrient; for example, LacprodanALPHA-10, a whey protein fraction with minimum 41\% ALA, was recently (2019) FDAapproved as an ingredient "generally recognized as safe" (GRAS) in infant formula to support the growth of infants. ${ }^{52}$ The protein was also shown to have a key role in the treatment of a number of human diseases, including some specific cancers in the complex HAMLET/BAMLET. In this respect, our study shows that once disintegrated in water, nanofibers release ALA molecules structurally resembling ALA in its native state. Via our approach, while keeping the original native structure, a novel nanofiber-based solid form of ALA can be adapted to the specific desired application. This makes our platform of even more general interest, and the relevance of our results spans from green chemistry and material sciences to drug delivery and biopharmaceutics.

\section{ASSOCIATED CONTENT}

\section{SI Supporting Information}

The Supporting Information is available free of charge at https://pubs.acs.org/doi/10.1021/acsanm.9b02557.

Setup for cross-linking of nanofibers with GTA vapor, cross-linking of nanofibers by heat treatment, supporting results of bacteria inhibition by ampicillin-loaded ALAbased nanofibers (PDF)

\section{AUTHOR INFORMATION}

\section{Corresponding Author}

Vito Foderà - Drug Delivery and Biophysics of Biopharmaceuticals, Department of Pharmacy, University of Copenhagen, Copenhagen 2100, Denmark; (1) orcid.org/00000003-2855-0568; Email: vito.fodera@sund.ku.dk 


\section{Authors}

Mai Bay Stie - Drug Delivery and Biophysics of Biopharmaceuticals, Department of Pharmacy, University of Copenhagen, Copenhagen 2100, Denmark

Michele Corezzi - Drug Delivery and Biophysics of Biopharmaceuticals, Department of Pharmacy, University of Copenhagen, Copenhagen 2100, Denmark

Adrian D. Juncos Bombin - Drug Delivery and Biophysics of Biopharmaceuticals, Department of Pharmacy, University of Copenhagen, Copenhagen 2100, Denmark

Fatemeh Ajalloueian - Nano-Bioscience Research Group, DTU-Food, Technical University of Denmark, Kgs. Lyngby 2800, Denmark

Erin Attrill - Living Systems Institute and Biosciences, University of Exeter, Exeter EX4 4QD, United Kingdom

Stefano Pagliara - Living Systems Institute and Biosciences, University of Exeter, Exeter EX4 4QD, United Kingdom; (1) orcid.org/0000-0001-9796-1956

Jette Jacobsen - Physiological Pharmaceutics, Department of Pharmacy, University of Copenhagen, Copenhagen 2100, Denmark

Ioannis S. Chronakis - Nano-Bioscience Research Group, DTU-Food, Technical University of Denmark, Kgs. Lyngby 2800, Denmark; 이 orcid.org/0000-0001-8339-3564

Hanne Mørck Nielsen - Drug Delivery and Biophysics of Biopharmaceuticals, Department of Pharmacy, University of Copenhagen, Copenhagen 2100, Denmark; (1) orcid.org/00000002-7285-9100

Complete contact information is available at: https://pubs.acs.org/10.1021/acsanm.9b02557

\section{Author Contributions}

V.F. developed the idea behind the project. V.F., H.M.N., I.S.C., J.J., M.B.S., and S.P. designed the experiments. M.B.S., M.C., A.D.J.B., F.A., and E.A. performed the experiments and analyzed the data. All authors contributed to the writing of the manuscript and approved the final version of the manuscript. M.B.S., M.C., and A.D.J.B. contributed equally to this work.

\section{Funding}

V.F. acknowledges the Villum Foundation for the Villum Young Investigator Grant "Protein Superstructures as Smart Biomaterials (ProSmart)” 2018-2023 (project number: 19175). H.M.N., I.S.C., J.J., and M.B.S. acknowledge The Danish Council for Independent Research; Technology and Production (DFF-6111-00333). F.A. also acknowledges the Danish Council for Independent Research; Technology and Production (4093-00282A, and 4217-00048A). This work was further supported by a Royal Society Research Grant (RG180007), an MRC Proximity to Discovery EXCITEME2 grant (MC_PC_17189), and a Welcome Trust Strategic Seed Corn Fund (WT-097835/Z/11/Z) awarded to S.P. E.A. was supported by an MRC CASE PhD studentship (MR/ P016162/1).

\section{Notes}

The authors declare no competing financial interest.

\section{ACKNOWLEDGMENTS}

Authors acknowledge Davisco Food International/Agropur Ingredients (Eden Prairie, MN) for kindly providing the $\alpha$ lactalbumin powder. Authors acknowledge Kleopatra Kalouta for assistance with circular dichroism experiments.

\section{REFERENCES}

(1) Bhardwaj, N.; Kundu, S. C. Electrospinning: A Fascinating Fiber Fabrication Technique. Biotechnol. Adv. 2010, 28 (3), 325-347.

(2) Khadka, D. B.; Haynie, D. T. Protein- and Peptide-Based Electrospun Nanofibers in Medical Biomaterials. Nanomedicine 2012, 8 (8), 1242-1262.

(3) Babitha, S.; Rachita, L.; Karthikeyan, K.; Shoba, E.; Janani, I.; Poornima, B.; Purna Sai, K. Electrospun Protein Nanofibers in Healthcare: A Review. Int. J. Pharm. 2017, 523 (1), 52-90.

(4) Schoolaert, E.; Ryckx, P.; Geltmeyer, J.; Maji, S.; Van Steenberge, P. H. M.; D'hooge, D. R.; Hoogenboom, R.; De Clerck, K. Waterborne Electrospinning of Poly(N-Isopropylacrylamide) by Control of Environmental Parameters. ACS Appl. Mater. Interfaces 2017, 9 (28), 24100-24110.

(5) Mendes, A. C.; Stephansen, K.; Chronakis, I. S. Electrospinning of Food Proteins and Polysaccharides. Food Hydrocolloids 2017, 68, $53-68$.

(6) Kowalczyk, T.; Nowicka, A.; Elbaum, D.; Kowalewski, T. A. Electrospinning of Bovine Serum Albumin Optimization and the Use for Production of Biosensors. Biomacromolecules 2008, 9 (7), 20872090.

(7) Valmikinathan, C. M.; Defroda, S.; Yu, X. Polycaprolactone and Bovine Serum Albumin Based Nanofibers for Controlled Release of Nerve Growth Factor. Biomacromolecules 2009, 10 (5), 1084-1089.

(8) Vega-Lugo, A. C.; Lim, L. T. Effects of Poly(ethylene oxide) and $\mathrm{pH}$ on the Electrospinning of Whey Protein Isolate. J. Polym. Sci., Part B: Polym. Phys. 2012, 50 (16), 1188-1197.

(9) Colín-Orozco, J.; Zapata-Torres, M.; Rodríguez-Gattorno, G.; Pedroza-Islas, R. Properties of Poly(ethylene oxide)/Whey Protein Isolate Nanofibers Prepared by Electrospinning. Food Biophys. 2015, 10 (2), 134-144

(10) Sullivan, S. T.; Tang, C.; Kennedy, A.; Talwar, S.; Khan, S. A. Electrospinning and Heat Treatment of Whey Protein Nanofibers. Food Hydrocolloids 2014, 35, 36-50.

(11) Livney, Y. D. Milk Proteins as Vehicles for Bioactives. Curr. Opin. Colloid Interface Sci. 2010, 15 (1-2), 73-83.

(12) Kimpel, F.; Schmitt, J. J. Review: Milk Proteins as Nanocarrier Systems for Hydrophobic Nutraceuticals. J. Food Sci. 2015, 80 (11), R2361-R2366.

(13) Markus, C. R.; Olivier, B.; De Haan, E. H. F. Whey Protein Rich in Alpha-Lactalbumin Increases the Ratio of Plasma Tryptophan to the Sum of the Other Large Neutral Amino Acids and Improves Cognitive Performance in Stress-Vulnerable Subjects. Am. J. Clin. Nutr. 2002, 75 (6), 1051-1056.

(14) Markus, C. R.; Olivier, B.; Panhuysen, G. E. M.; Van Der Gugten, J.; Alles, M. S.; Tuiten, A.; Westenberg, H. G. M.; Fekkes, D.; Koppeschaar, H. F.; De Haan, E. E. H. F. The Bovine Protein AlphaLactalbumin Increases the Plasma Ratio of Tryptophan to the Other Large Neutral Amino Acids, and in Vulnerable Subjects Raises Brain Serotonin Activity, Reduces Cortisol Concentration, and Improves Mood under Stress. Am. J. Clin. Nutr. 2000, 71 (6), 1536-1544.

(15) Booij, L.; Merens, W.; Markus, C. R.; Van der Does, A. J. W. Diet Rich in Alpha-Lactalbumin Improves Memory in Unmedicated Recovered Depressed Patients and Matched Controls. J. Psychopharmacol. 2006, 20 (4), 526-535.

(16) Markus, C. R.; Jonkman, L. M.; Lammers, J. H. C. M.; Deutz, N. E. P.; Messer, M. H.; Rigtering, N. Evening Intake of AlphaLactalbumin Increases Plasma Tryptophan Availability and Improves Morning Alertness and Brain Measures of Attention. Am. J. Clin. Nutr. 2005, 81 (5), 1026-1033.

(17) Lien, E. L.; Davis, A. M.; Euler, A. R. Growth and Safety in Term Infants Fed Reduced-Protein Formula with Added Bovine Alpha-Lactalbumin. J. Pediatr. Gastroenterol. Nutr. 2004, 38 (2), 170176.

(18) Trabulsi, J.; Capeding, R.; Lebumfacil, J.; Ramanujam, K.; Feng, P.; McSweeney, S.; Harris, B.; DeRusso, P. Effect of an AlphaLactalbumin-Enriched Infant Formula with Lower Protein on Growth. Eur. J. Clin. Nutr. 2011, 65, 167-174. 
(19) Roze, J.-C.; Barbarot, S.; Butel, M.-J.; Kapel, N.; WaligoraDupriet, A.-J.; De Montgolfier, I.; Leblanc, M.; Godon, N.; Soulaines, P.; Darmaun, D.; Rivero, M.; Dupont, C. An Alpha-LactalbuminEnriched and Symbiotic-Supplemented v. a Standard Infant Formula: A Multicentre, Double-Blind, Randomised Trial. Br. J. Nutr. 2012, $107,1616-1622$.

(20) Ng, T. B.; Cheung, R. C. F.; Wong, J. H.; Wang, Y.; Ip, D. T. M.; Wan, D. C. C.; Xia, J. Antiviral Activities of Whey Proteins. Appl. Microbiol. Biotechnol. 2015, 99 (17), 6997-7008.

(21) Svanborg, C.; Agerstam, H.; Aronson, A.; Bjerkvig, R.; Duringer, C.; Fischer, W.; Gustafsson, L.; Hallgren, O.; Leijonhuvud, I.; Linse, S.; Mossberg, A.-K.; Nilsson, H.; Pettersson, J.; Svensson, M. HAMLET Kills Tumor Cells by an Apoptosis-like Mechanism - Cellular, Molecular, and Therapeutic Aspects. Adv. Cancer Res. 2003, 88, 1-29.

(22) Håkansson, A.; Zhivotovsky, B.; Orrenius, S.; Sabharwal, H.; Svanborg, C. Apoptosis Induced by a Human Milk Protein. Proc. Natl. Acad. Sci. U. S. A. 1995, 92 (17), 8064-8068.

(23) Gustafsson, L.; Leijonhufvud, I.; Aronsson, A.; Mossberg, A.; Svanborg, C. Treatment of Skin Papillomas with Topical AlphaLactalbumin-Oleic Acid. N. Engl. J. Med. 2004, 350, 2663-2672.

(24) Mossberg, A. K.; Wullt, B.; Gustafsson, L.; Månsson, W.; Ljunggren, E.; Svanborg, C. Bladder Cancers Respond to Intravesical Instillation of HAMLET (Human $\alpha$-Lactalbumin Made Lethal to Tumor Cells). Int. J. Cancer 2007, 121 (6), 1352-1359.

(25) Fischer, W.; Gustafsson, L.; Mossberg, A.-K.; Gronli, J.; Mork, S.; Bjerkvig, R.; Svanborg, C. Human Alpha-Lactalbumin Made Lethal to Tumor Cells (HAMLET) Kills Human Glioblastoma Cells in Brain Xenografts by an Apoptosis-like Mechanism and Prolongs Survival. Cancer Res. 2004, 64, 2105-2112.

(26) Puthia, M.; Storm, P.; Nadeem, A.; Hsiung, S.; Svanborg, C. Prevention and Treatment of Colon Cancer by Peroral Administration of HAMLET (Human $\alpha$-Lactalbumin Made Lethal to Tumour Cells). Gut 2014, 63 (1), 131-142.

(27) Rammer, P.; Groth-Pedersen, L.; Kirkegaard, T.; Daugaard, M.; Rytter, A.; Szyniarowski, P.; Hoyer-Hansen, M.; Povlsen, L. K.; Nylandsted, J.; Larsen, J. E.; Jäätelä, M. BAMLET Activates a Lysosomal Cell Death Program in Cancer Cells. Mol. Cancer Ther. 2010, 9 (1), 24-32.

(28) Roylance, D. Stress-Strain Curves; MIT Press: Cambridge, MA, 2001.

(29) Hassan, E. E.; Gallo, J. M. A Simple Rheological Method for the in Vitro Assessment of Mucin-Polymer Bioadhesive Bond Strength. Pharm. Res. 1990, 7 (5), 491-495.

(30) Nieuwland, M.; Geerdink, P.; Brier, P.; Van Den Eijnden, P.; Henket, J. T. M. M.; Langelaan, M. L. P.; Stroeks, N.; Van Deventer, H. C.; Martin, A. H. Food-Grade Electrospinning of Proteins. Innovative Food Sci. Emerging Technol. 2014, 24, 138-144.

(31) Saquing, C. D.; Tang, C.; Monian, B.; Bonino, C. A.; Manasco, J. L.; Alsberg, E.; Khan, S. A. Alginate-Polyethylene Oxide Blend Nanofibers and the Role of the Carrier Polymer in Electrospinning. Ind. Eng. Chem. Res. 2013, 52 (26), 8692-8704.

(32) Xie, J.; Wang, C. H. Electrospun Micro- and Nanofibers for Sustained Delivery of Paclitaxel to Treat C6 Glioma in Vitro. Pharm. Res. 2006, 23, 1817-1826.

(33) Chen, S. C.; Huang, X. B.; Cai, X. M.; Lu, J.; Yuan, J.; Shen, J. The Influence of Fiber Diameter of Electrospun Poly(Lactic Acid) on Drug Delivery. Fibers Polym. 2012, 13 (9), 1120-1125.

(34) Sisson, K.; Zhang, C.; Farach-Carson, M. C.; Chase, D. B.; Rabolt, J. D. Fiber Diameters Control Osteoblastic Cell Migration and Differentiation in Electrospun Gelatin. J. Biomed. Mater. Res., Part A 2010, 94A (4), 1312-1320.

(35) Permyakov, E. A.; Berliner, L. J. Alpha-Lactalbumin: Structure and Function. FEBS Lett. 2000, 473, 269-274.

(36) Borro, B. C.; Parolini, L.; Cicuta, P.; Fodera, V.; Di Michele, L. Interaction with Prefibrillar Species and Amyloid- like Fibrils Changes the Stiffness of Lipid Bilayers. Phys. Chem. Chem. Phys. 2017, 19, 27930-27934.
(37) Nguyen, T.-H.; Lee, B.-T. Fabrication and Characterization of Cross-Linked Gelatin Electro-Spun Nano-Fibers. J. Biomed. Sci. Eng. 2010, 3, 1117-1124.

(38) Akhshabi, S.; Biazar, E.; Singh, V.; Keshel, S. H.; Nagaraja, G. The Effect of Glutaraldehyde Cross-Linker on Structural and Biocompatibility Properties of Collagen-Chondroitin Sulfate Electrospun Mat. Mater. Technol. 2018, 33 (4), 253-261.

(39) Arya, A.; Chandra, A.; Sharma, V.; Pathak, K. Fast Dissolving Oral Films: An Innovative Drug Delivery System and Dosage Form. Int. J. Chem. Tech Res. 2010, 2 (1), 576-583.

(40) Li, X.; Kanjwal, M. A.; Lin, L.; Chronakis, I. S. Electrospun Polyvinyl-Alcohol Nanofibers as Oral Fast-Dissolving Delivery System of Caffeine and Riboflavin. Colloids Surf., B 2013, 103, 182-188.

(41) Laha, A.; Sharma, C. S.; Majumdar, S. Sustained Drug Release from Multi-Layered Sequentially Crosslinked Electrospun Gelatin Nanofiber Mesh. Mater. Sci. Eng., C 2017, 76, 782-786.

(42) Vass, P.; Démuth, B.; Hirsch, E.; Nagy, B.; Andersen, S.; Vigh, T.; Verreck, G.; Csontos, I.; Nagy, Z.; Marosi, G. Drying technology strategies for colon-targeted oral delivery of biopharmaceuticals. J. Controlled Release 2019, 296, 162-178.

(43) Destaye, A. G.; Lin, C. K.; Lee, C. K. Glutaraldehyde Vapor Cross-Linked Nanofibrous PVA Mat with in Situ Formed Silver Nanoparticles. ACS Appl. Mater. Interfaces 2013, 5 (11), 4745-4752.

(44) Zhang, Y. Z.; Venugopal, J.; Huang, Z. M.; Lim, C. T.; Ramakrishna, S. Crosslinking of the Electrospun Gelatin Nanofibers. Polymer 2006, 47 (8), 2911-2917.

(45) Wang, W.; Jin, X.; Zhu, Y.; Zhu, C.; Yang, J.; Wang, H.; Lin, T. Effect of Vapor-Phase Glutaraldehyde Crosslinking on Electrospun Starch Fibers. Carbohydr. Polym. 2016, 140, 356-361.

(46) Wingate, K.; Bonani, W.; Tan, Y.; Bryant, S. J.; Tan, W. Compressive Elasticity of Three-Dimensional Nanofiber Matrix Directs Mesenchymal Stem Cell Differentiation to Vascular Cells with Endothelial or Smooth Muscle Cell Markers. Acta Biomater. 2012, 8 (4), 1440-1449.

(47) Stephansen, K.; García-Díaz, M.; Jessen, F.; Chronakis, I. S.; Nielsen, H. M. Bioactive Protein-Based Nano Fibers Interact with Intestinal Biological Components Resulting in Transepithelial Permeation of a Therapeutic Protein. Int. J. Pharm. 2015, 495 (1), $58-66$.

(48) Six, D. A.; Krucker, T.; Leeds, J. A. Advances and Challenges in Bacterial Compound Accumulation Assays for Drug Discovery. Curr. Opin. Chem. Biol. 2018, 44, 9-15.

(49) Smith, A.; Kaczmar, A.; Bamford, R. A.; Smith, C.; Frustaci, S.; Kovacs-Simon, A.; O’Neill, P.; Moore, K.; Paszkiewicz, K.; Titball, R. W.; Pagliara, S. The Culture Environment Influences Both Gene Regulation and Phenotypic Heterogeneity in Escherichia Coli. Front. Microbiol. 2018, 9, 1739 DOI: 10.3389/fmicb.2018.01739.

(50) Keren, I.; Kaldalu, N.; Spoering, A.; Wang, Y.; Lewis, K. Persister Cells and Tolerance to Antimicrobials. FEMS Microbiol. Lett. 2004, 230 (1), 13-18.

(51) Bamford, R. A.; Smith, A.; Metz, J.; Glover, G.; Titball, R. W.; Pagliara, S. Investigating the Physiology of Viable but Non-Culturable Bacteria by Microfluidics and Time-Lapse Microscopy. BMC Biol. 2017, 15 (121), 1-12.

(52) GRAS notice (GRN No. 809). U.S. Food and Drug Administration, 2019. Available from https://www.accessdata.fda. gov $/$ scripts $/ \mathrm{fdcc} /$ ?set=GRASNotices\&id=809. 